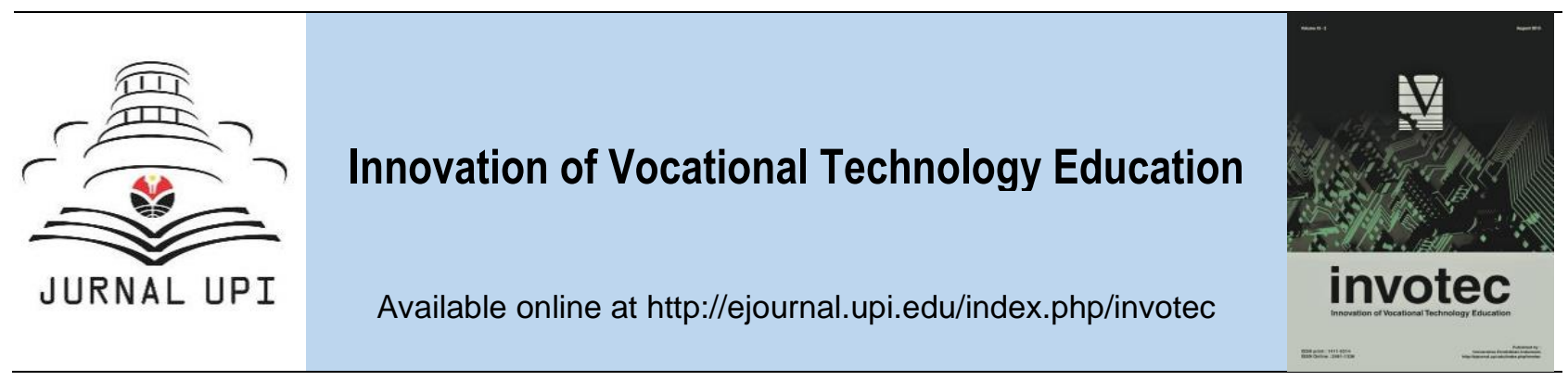

\title{
Effectiveness of Technical Training Interns in Skills Application in Nyeri County, Kenya
}

\author{
E. Waihura ${ }^{1}$, J. Kagema ${ }^{2}$, and P. Kimiti ${ }^{3}$ \\ ${ }^{1}$ Department of Applied Sciences, The Nyeri National Polytechnic, Kenya \\ 2 Department of Education, Karatina University, Kenya \\ ${ }^{3}$ Department of Planning, Administration and Curriculum Studies, Machakos University, Kenya.
}

\section{ARTICLE INFO}

Article history:

Received 15 November 2018

Received in revised form 12 December 2018

Accepted 12 January 2019

Available online 28 February 2019

Keywords:

technical training interns

skills application

experience in work place

Corresponding author:

ewaihura19@gmail.com

\section{A B S T R A C T}

Technical, industrial, vocational and entrepreneurship training Institutions (TIVET) are a key component to provide the required human resource to achieve Kenya's Vision 2030. This study sought to find out the effectiveness of technical training interns in skills application in Nyeri County, Kenya. The study sought to establish the industrial supervisors' attitude towards competence of technical training interns in the work-place. The study was guided by Context, Input, Process and Product (CIPP) Theory. The study adopted a descriptive survey research design with a target population was 10 Heads of Applied Sciences Department, 45 supervisors from the companies within Aberdare's Region that offers a technical and practical based internship to interns from technical training institutions. The sample used in the study comprised of 73 respondents comprising of $10 \mathrm{HODs}$ and eight supervisors'. Purposive sampling was used to select the HODs and Supervisors' for the study. The questionnaire and the interview guide were piloted to test for reliability and validity. The reliability coefficient for the TIVET Heads of Department Questionnaire was 0.767. Inferential and descriptive statistics was applied to analyse data with aid of SPSS computer program. The study established a mean of 1.62 and standard deviation of 0.774 to the statement. The findings show that the supervisors' thought the TIVET curriculum was theoretical to some extent. $25 \%$ and $37.5 \%$ indicated that they strongly disagreed and disagreed respectively to the statement that TIVET curriculum was in line with the current technology in the country. The study concludes that technical and vocational education is the core driver for countries the world over to achieve envisaged steps in economic and technological development. Ensuring that curriculum of TIVET education be more practical based will make this education effective. The authors recommend that the attachment period should be extended to enhance the interns' effectiveness and application of knowledge through hands-on experience in real production work. 


\section{Introduction}

Technical training was viewed as a strategy to bridge the gap that existed once the expatriates left when the African countries gained independence. Lauglo (2005) in his study on TIVET in SubSaharan Africa noted that since 1970s, TIVET attracted increased government funding to enhance production of highly skilled mid-level managers for the expected increase in demand for labour in the production companies for developing economy. Lauglo (2005) indicated that as a result of these developments African governments set up technical and vocational education institutions based on colonial education model. The main aim of African governments was to raise individuals' job prospects and productivity. Konayuma (2008) suggested that graduate education provided a fast track to the most powerful and prestigious positions in the available occupations. As a result, enterprises were expected to become more competitive and to make a greater contribution to economic growth, on condition that those trained in these institutions actually matched the requirements of the labour market. A study carried out in Ghana on challenges that face technical training noted that the major issues that affect the quality of trainees included inadequate equipping of technical training centers (Dasmani, 2011). In Ghana various ways of overcoming challenges in technical training called for collaboration between the various agencies and government.

Nirmala, et. al. (2012) argued that TIVET continued to attract a great deal of criticism due to the nature of the trainees from the TIVET. Nirmala et. al. (2012) noted that TIVET were unable to train skilled workers to meet the requirements of enterprises and were unaware of the market needs. They also held that the TIVET were very costly and often their trainees joined the pool of unemployed trainees from the mainstream higher education an indication that the training provided did not match the jobs available.

A study conducted by Simiyu (2009) in Kenya noted that to start with the community had great regard to technical training centers competence to produce very competent trainees. However, the study noted that in the new century the quality and competence level of trainees of technical trainees has been falling owing to technology and competence of trainers in the facilities. In many countries, including Ghana, public TIVET institutions have not been able to adapt to the new structure of the labour market and the new skill requirements of companies in both the formal and informal sectors. Ayuba (2000) posited that some African countries have made TIVET a post-basic education in order to provide the much needed technical personnel needed to drive growth and expansion at mid-level management.

Technical training institutions were intended to train mid-level managers and practical skilled personnel to support the Kenyan independent economy. However, as the level of funding from the government plummeted, the quality of training offered in technical institutions became poor and the public lost confidence in the TIVET. The national and county government move under the new constitutional dispensation has put more emphasis on technical training. However, the TIVET still attract some students while many keep away to join the universities. The managers of many companies have also complained on the effectiveness of the trainees from the TIVET. Despite these interventions to encourage Kenyans to join technical institutions and inform the Kenyans on the importance of technical institutions, the same has not translated into increased enrollment in these institutions.

Gachie (2013) argues that there are approximately 800 technical institutions with majority of them being registered by the Directorate of Technical Accreditation and Quality Assurance with the rest holding provisional registration. No technical institute is allowed to operate in Kenya without being issued with a certificate from the Ministry of Basic and Higher Education. Currently there is a TIVET Authority that is charged with licensing, registering, accrediting, monitoring and evaluating training institutions to protect parents and trainees from fraudsters seeking profits.

Tilak (2002) posits that it was commonly accepted that all forms of education would help people to improve themselves and to get better jobs, but many parents shunned TIVET for university education which they deemed would offer their children the opportunity to acquire a good job. As a result, many countries found that the number of trainees from universities far exceeded the capacity of the labour market to provide appropriate employment. At the same time, these countries are unable to attract enough people to train for those positions of greater need, which might be ,blue collar' jobs that might appear to involve manual labour, be dangerous, dirty and difficult.

In Uganda, noted that the supervisors and mid-level managers who are charged with induction of newly employed trainees noted that the trainees of technical institutions were not as competent compared to mainstream trainees. This was attributed to ill-equipped facilities used to train the 
trainees and poor trainers. Most technical institutions have also been converted into constituent colleges of mainstream universities as the communities favour university education compared to technical training.

The American higher education has experienced massive expansion since Second World War. Bunning (2006) observed that by the year 2000 there were approximately 4,200 institutions of higher education in the United States that would have enrolled over 15.3 million trainees. They noted that by 2001 , over $60 \%$ of the United States' high school trainees would have attended colleges. Bunning (2006) also noted that the American higher education is increasingly stratified. This trend may suggest that training programmes offered by the technical institutes probably has failed to develop the skills required for the job market within the region and beyond. The technical institutions have also relied heavily on obsolete technology in their training programmes and hence affected the effectiveness of the trainees. Hence the need to assess the effectiveness of trainees of technical.

This study was based on the Context, Input, Process and Product Theory (CIPP) as explained by Zang, et. al., (2011). The theory holds that obtaining information about a situation to decide on educational needs and to establish programme objectives. Felten, Gilchrist and Darby (2006) noted that CIPP Theory is recommended as a framework to systematically guide the conception, design, implementation and assessment of learning programmes and thus provide feedback and judgment of programmes effectiveness for continuous improvements. From the theory, the training programme offered in technical institutions in Kenya should be systematic and cater for the changing technological advancements in the country in order for the programme to be relevant and useful. This study seeks to analyse the input (learners' attitudes), process (training programmes) and product (quality of trainees) of TIVET.

By investigating the trainees' attitudes and employers' attitudes on TIVET training, this study will gather information on the needs that these two components view as inadequate and needs review. Karayan and Gathercoal (2005) noted that CIPP Theory seeks to analyses the inputs by identifying educational strategies likely to achieve results. By analyzing the process, $t \neg \neg$ he theory also holds that gathering of information regarding the results of educational process which forms the ultimate goal of this study by analyzing the mismatch that might be existing between TIVET training and the real job market requirement.

\section{Method}

This study adopted a descriptive survey design. The study adopted a descriptive survey research design with a target population was 10 Heads of Applied Sciences Department, 45 supervisors from the companies within Aberdares Region in Kenya that offers technical practical based internship to interns from technical training institutions. The sample used in the study comprised of 73 respondents comprising of 10 HODs and eight supervisors'. Purposive sampling was used to select the HODs and Supervisors' for the study.

Kombo and Tromp (2006) defines sampling as the process of selecting a number of individuals or objects from a population such that the selected group contains elements representative of the characteristics found in the entire group. The study applied Gay (2003) principle in determining the sample size. Gay indicated that a sample of between $10 \%$ and $20 \%$ of the population is adequate for large and small populations respectively. Analysis of the respondent's age was done and shows that all the HODs were aged above 39 years. The study assessed the data using open-ended and closed questions to focus on the attitudes of the HODs and the Intern Supervisors' on the effectiveness of the interns of technical training institutions. A series of statements using a five-point Likert scale was used where strongly disagree (5), disagree (4), undecided (3), agree (2) and strongly agree (1). The interview guide provided open-ended statements to collect data from the supervisors'.

The study employed a questionnaire and interview guide as the primary data collection instrument. The instruments were designed in a simple and straight forward language making it easy for the respondent to work on them. The questionnaire consisted of both open-ended and closed questions which had been designed specifically for the respondents in line with the research objectives. The questionnaires enabled the person administering them to explain the purpose of the study and the meaning of items that might not have been clear and the anonymity in them helped the researcher to produce more candid answers than is possible in an interview. 


\section{Result and Discussion}

Data revealed that half of the HODs indicated that they strongly disagreed with the statement that TIVET curriculum lacked the linkage into world of work whereas relatively less than half $(41.7 \%)$ of the trainees disagreed with the statement. Data also shows that half of the HODs agreed with the statement. The study established that the respondents were divided whether the TIVET Curriculum has a linkage with the current job market requirements although the trainees agreed they found a link between their curriculum and the job market requirements. This means that the trainees were positive on the type of training they received in the technical institutes. The study showed that majority of the trainees had positive attitudes towards technical skill involved in technical education. The study also noted that there was a positive relationship between trainees' attitude in technical skill acquisition and their performance. The study sought the supervisors' attitude towards the TIVET curriculum and their responses are summarized in Table 1.

Table 1. TIVET curriculum theory oriented

\begin{tabular}{lcccc}
\multicolumn{5}{c}{ Table 1. TIVET curriculum theory oriented } \\
\hline \multirow{2}{*}{ Responses } & Supervisors & \multicolumn{2}{c}{ Trainees } \\
\hline Strongly Disagree & 0 & 0 & 1 & 2.1 \\
Disagree & 3 & 37.5 & 10 & 20.8 \\
Agree & 4 & 50 & 37 & 77.1 \\
Strongly Agree & 1 & 12.5 & 0 & 0 \\
\hline Total & 8 & 100 & 48 & 100 \\
\hline
\end{tabular}

Data analyzed showed that of the eight TIVET HODs who took part in the study, a minority $(37.5 \%)$ indicated they disagreed that the TIVET curriculum is theory based, majority of the HODs agreed with the statement. Data also showed that $2.1 \%, 20.8 \%$ and $77.1 \%$ of the trainees who participated strongly disagreed, disagreed and agreed with the statement respectively. From this analysis, the study noted that majority of the supervisors and trainees agreed that the current TIVET curriculum is theory based.

The supervisors' indicated either, 'Yes', 'To Some Extent' and 'No' to the statement that curriculum offered in TIVET was theory based. This data was coded and analyzed where yes (1), to some extent (2) and No (3) with a mean of 1.62 and standard deviation of 0.774 to the statement. The findings show that the supervisors' thought the TIVET curriculum was theoretical as found from $63 \%$ of the respondents.

The supervisors' were asked to highlight some areas that they thought the trainees miss out in their training and which necessitated the supervisors' to be more careful when engaging these trainees. Analysis of the supervisors" reasons comprised the following key areas: Lack of required practical exposure, lack of knowledge working with machinery, and general lack of knowledge and these were summarized as shown in Table 2.

Table 2. Areas TIVET trainees miss out

\begin{tabular}{lcc}
\hline Areas Missed Out & Percent & Cumulative frequency \\
\hline Practical experience & 37.5 & 37.5 \\
Accustomed to Machinery & 50 & 87.5 \\
General Lack of Knowledge & 12.5 & 100 \\
\hline
\end{tabular}

Analysis of the Supervisors' responses showed that $37.5 \%, 50.0 \%$ and $12.5 \%$ indicated that practical experience, accustomed to using machinery and general lack of knowledge was the areas that TIVET trainees missed out on. This means that majority of the TIVET trainees missed out more on practical experience. The respondents were asked to indicate their response if the current TIVET curriculum is up to date with the technology and the responses are summarized in Table 3. 
Table 3. TIVET curriculum is in line with current technology

\begin{tabular}{lcc}
\hline & Percent & Cumulative frequency \\
\hline Strongly Disagree & 25.0 & 25.0 \\
Disagree & 37.5 & 62.5 \\
Undecided & 0 & 62.5 \\
Agree & 0 & 62.5 \\
Strongly Agree & 37.5 & 100 \\
\hline
\end{tabular}

Data in Table 3 shows that of the HODs who participated, $25 \%$ and $37.5 \%$ indicated that they strongly disagreed and disagreed respectively to the statement that TIVET curriculum was in line with the current technology in the country whereas another $37.5 \%$ indicated they strongly agreed with the statement. Analysis also showed that $47.92 \%$ of the trainees agreed with the statement while another $25 \%$ were undecided and another $8.34 \%$ disagreed with statement. The study found that there were conflicting reports from the two categories of respondents (HODs and the Trainees). Analysis of the responses from the interview with the supervisors was sought concerning the curriculum as summarized in Figure 1.

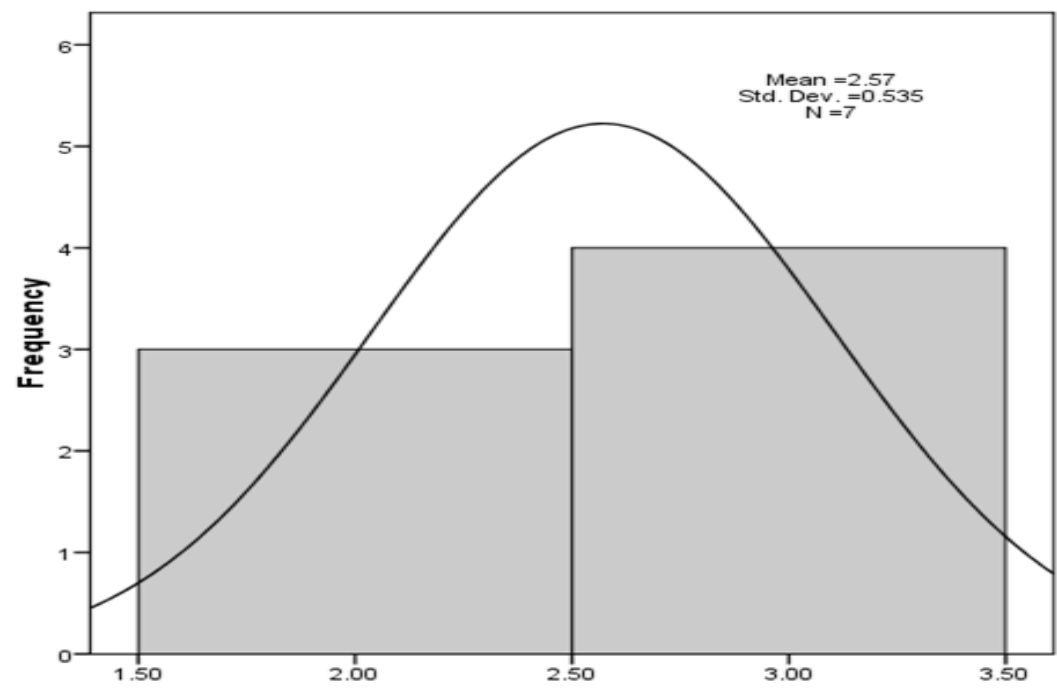

Figure 1. Supervisors' views on curriculum and level of technology

Analysis of supervisors' responses shown in Figure 1 indicates that the mean of the supervisors' responses shows that the mean of 2.57 and standard deviation of 0.535 to the response that the TIVET curriculum is in line with the current technology. The responses varied from very large extent (1), large extent (2), low extent (3) and very low extent (4). A mean of 2.57 shows that the respondents indicated that the curriculum was in line with the prevailing technology to a low extent and such it needed to the current technology level. The study sought to establish if the supervisors would recommend the TIVET trainees in their institutions and their responses are summarized in Table 4.

Table 4. Supervisors' recommendations for TIVET trainees employment

\begin{tabular}{lcc}
\hline & Percent & Cumulative Percent \\
\hline Yes & 50 & 50 \\
Somehow & 37.5 & 87.5 \\
Not at all & 12.5 & 100 \\
\hline
\end{tabular}

The data shows that $50 \%$ of the supervisors' indicated affirmatively yes they would recommend the TIVET trainees to be placed in their institutions whereas $37.5 \%$ indicated they would somehow recommend TIVET trainees. Data also reveals that $12.5 \%$ of the supervisors' agreed they would not 
recommend TIVET trainees placement in their firms. The findings show that TIVET trainees would not be recommended by half of the supervisors would not recommend the TIVET trainees to be employed in their institutions. This shows the open dispute on the quality of trainees from technical institutions in Kenya.

The findings concur with UNESCO (2006) that majority of the technical institutions have well organized programmes that learners undertake. These programmes were noted by UNESCO to cater for self-employment after graduation or employment into technical departments. Islam and Mia (2007) study in Bangladesh revealed that formal and informal technical training missed out on effective linkages between the programs and the industry needs. The study agrees with the concurs that technical institutes have well organized curriculum as was also evidenced by the various technical institutes brochures.

\section{Conclusion}

The curriculum offered in technical training was more theory based rather than practical based content. The interns were also noted to lack practical based knowledge and were not accustomed to types of machinery found in the work-place. This affected their competency levels during the periods they were attached in the companies. The supervisors' argued that the training programmes should incorporate more attachment-based learning to enhance the interns' effectiveness and efficiency after the years of schooling to orient the interns on current industrial technology and application. The study therefore concludes that technical and vocational education is the core driver for countries the world over to achieve envisaged steps in economic and technological development.

\section{References}

Ayuba, A. (2000). The role of Technical and Vocational Education and Training in Human Resource Development. The Case of Turba Village of Technology.

Bunning, F. (2006). TIVET Teacher Education on the Threshold of Internationalisation. Bonn: Internationale-Weiterbildung und EntwicklungGgmbh.Rwanda.

Dasmani, A. (2011). Challenges facing Technical Institute Trainees in Practical Skills Acquisition in the Upper East Region of Ghana. Asia-Pacific Journal of Cooperative Education. 12(2): 67-77.

Felten, P., Gilchrist, L. Z., and Darby, A. (2006). Emotion and learning: Feeling our way toward a new theory of reflection in service-learning. Michigan Journal of Community Service Learning. 12(2):38-46.

Gachie, J. (2013). Technical Education in Kenya. Retrieved November, 10, 2014, from Soft Kenya: http://softkenya.com/technical-education-in-kenya/

Gay, R. L. (2003). Educational Research: Competencies for Analysis and Application (7th ed.) Columbus: Charles E. and Merrill Publishing Company.

Islam, R., and Mia, A. (2007). The role of education for rural population transformation in Bangladesh. Asia-Pacific Journal of Cooperative Education. 8(1):1-21.

Karayan, S., and Gathercoal, P. (2005). Assessing service-learning in Teacher Education. Teacher Education Quarterly. 32(3):79-92.

Kombo, K. and Tromp, A. (2006). Proposal and Thesis Writing. Nairobi: Pauline's Publications Africa.

Konayuma, G. S. (2008). Achieving Poverty Reduction through Quality Vocational Education and Training in Partnership with Industry. Livingstone: IVETA. 
Lauglo. (2005). Cited in Lan Joo. World Bank Institute, extracted on 11th July 2014. Proposal and Thesis Writing. Nairobi: Pauline's Publications Africa.

Nirmala, M., Karthikeyan, K., Appalabatla, S., and Patharaj, J. (2012). The Role of ICT in the Economic Development of North East Africa: Eritrea. Journal of Emerging Trends in Computing and Information Sciences. 3(3):310-318.

Simiyu, J. (2009). Revitalizing a Technical Training Institute in Kenya. A Case Study of Kaiboi Technical Training Institute. UNESCO.

Tilak, J. (2002). Vocational Education and Training and Asia: The Handbook on Educational Research in the Asia. Pacific Region (eds. John P. Keeves and Rye Watanabe). Kluwer: Academic Publishers.

UNESCO. (2006). Guidebook for Planning Education in Emergencies and Reconstruction (UNESCO/IIEP).

Zang, G., Zeller, N., Griffith, R., Metcalf, D., Williams, J., Shea, C., and Misulis, K. (2011). Using the Context, Input, Process and Product Evaluation Model (CIPP) as a Comprehensive Framework to Guide the Planning, Implementation and Assessment of Service Learning Programs. Journal of Higher Education, Outreach and Engagement. 15(4):57-84. 